\title{
The Analysis of English Humor from the Perspective of Pragmatic Principle
}

\author{
Zhen Zhou \\ Foreign Languages College, Nanchang Normal University, Nanchang, Jiangxi, 330032, China \\ zoye100@sina.com
}

\begin{abstract}
Keywords: Humor; The pragmatic principle; The referential expression; Prerequisite; The Cooperative principle; Verbal behavior
\end{abstract}

\begin{abstract}
Humor is a ubiquitous, highly rooted and largely meaningful aspect of human experience, an ordinary communicative way in human's daily life and it is an indispensable phenomenon in every language and culture, which can facilitate social interactions and can enrich and beautify human's life. The article analyzes the relationship between the pragmatic principle and English humor employing particular examples of English humor, from the aspect of pragmatic research, namely, the referential expression, prerequisite, the cooperative principle, and verbal meaning, aiming to enable readers to gain a deeper understanding on the phenomenon of English humor and enhance readers' pragmatic ability to carry out successful English communication, which facilitates the English teaching and learning as well.
\end{abstract}

\section{Introduction}

Humour (in Commonwealth English), or humor (in American English) is the tendency of particular cognitive experiences to provoke laughter and provide amusement. The term derives from the humoral medicine of the ancient Greeks, which taught that the balance of fluids in the human body, known as humours (Latin: humor, "body fluid"), controlled human health and emotion [1]. Humor is also a language art, and is a kind of culture, which is a reflection and symbolization of human beings' civilization and wisdom. Humor is the viewpoints or perspectives expressed in the way of concise, lively, vivid, funny, or exaggerating words based on people's profound understanding on the realistic life, which is often amusing, inspiring, thought-provoking, and eliciting [2, 3, 4]. Humor not only bears the feature of strong language pragmatism, but it can also reflect the characteristics and regularities from various layers. The appearance and using of humor not only is closely related to the inner law of language itself, but also largely depends on the application of the language in contexts [5, 6, 7]. Pragmatics conducts studies on the special language in special situations, especially on the rules in respect to how to employ and comprehend language in different language communicative situations [8, 9]. The article analyzes the relationship between the pragmatic principle and English humor employing particular examples of English humor, from the aspect of pragmatic research, including the referential expression, prerequisite, the cooperative principle, and verbal meaning, aiming to enable readers to achieve a deeper understanding of the phenomenon of English humor.

\section{The Referential Expression and Humor}

The referential expression is an important research topic in pragmatics, including the linguistic forms or linguistic expressing forms with referential function, which can aid the receivers or readers to discern some particular thing or person. It mainly consists of the following types: a) proper nouns; b) definite descriptive language, such as: the composer; b) indefinite descriptive language, such as: a lake. d) Pronouns, including personal pronouns and demonstrative pronouns, such as: you, him, it, this and etc. Of the pronouns, there is a special referential expressing, which is isolated referential expression and has abstract and static denotation, but the referential meaning may be dynamic, changing with speaker's communicative intentions in the language communication activities. If the isolated referential expression is separated from certain specific contexts, the communicative 
function and value will discount to a large extent. If speakers participating in the communication have some deviation, dislocation, or purposeful misinterpretation of the referential expressions, the referential object will be wrong or chaotic, thus giving birth to the humorous effect. For example:

Nurse: (coaxing): Now let's take off our clothes and see how much we weigh.

Boy: You go ahead. I don't want to.

In the conversation, since the nurse intends to show her kindness, caring and equality to the little boy in order to intensify the boy's good impression of her, she uses "let's", namely, let us. However the boy maybe does not understand the pragmatic meaning of the referential pronoun of the pronoun, or merely avoid the actual meaning deliberately, turn nurse's trick to her own use, thus causing the effect of humor.

\section{The Prerequisite and Humor}

The prerequisite is composed of logic-meaning prerequisite and pragmatic prerequisite [10]. The logic-meaning prerequisite, analyzes from the aspect of logic and meaning, involving the proposition relationship of utterances, various logic relationships, the influence of lexical meaning and structure meaning of the utterances. The pragmatic prerequisite refers to adaptation logic, the framework of pragmatic analysis, and making a research into prerequisite in a particular context, which is largely influenced by contexts. But there is no clear distinction between the two types of prerequisite. In the research of logic-meaning prerequisite, the prerequisite trigger is an intriguing topic, while pragmatic prerequisite attaches much attention to the common background knowledge of two communicative parts. In the influence of contexts, the conversational meaning of utterances can vanish. The reversibility of prerequisite means that the utterance with the prerequisite appear previously, the speaker later designs this kind of suspense prerequisite, and then creates humor through negating the prerequisite, or makes some utterances contradicting to the prerequisite. For example:

The Englishman who sat next to me was a complete fool. He asked me what I thought of Hemingway. Well, wanted to laugh in his face. I don't know anyone by this name. Why would he think I did? So I told him that our country is very big, and that I don't know everyone in it. But I added, someday I may meet Hemingway. Is he also in the blue jeans business, I asked? Well, I think the Englishman felt a little bit foolish. He just said no, and then got up and left the table.

This humorous story produces humor because the utterance prerequisite invalidates. In the story, the pragmatic prerequisite is that "I" don't know that Hemingway is a famous American writer, thus the speaker and the receiver can not communicate well. "I" think that I am wise, but in my own conceit, saying out a series of silly words. And the story writer just utilizes the pragmatic prerequisite invalidity to achieve the humorous effect.

\section{The Cooperative Principle and Humor}

In the process of communicative process, the two parts must abide by some basic principle in order to guarantee the smooth advance of the conversation, especially abide by the cooperative principle. How people obey the cooperative principle to achieve mutual understanding, mutual coordination and realize the conversational goals is a big issue. American philosopher Grice summarize that the cooperative principle comprise of four parts through systematically summarizing the communicative behaviors, that is, the quantity maxim, the quality maxim, the relation maxim, and the manner maxim [11]. If either part of the communication disobeys one or some articles of the principles on purpose or by accident, the communicative effect will be affected largely inevitably, causing the inconsistence of the subjective will and the actual objective effect. It is the very inconsistence that is the main reason to generate humor. Thus, violating the cooperative principle deliberately or unintentionally often results in humor. 
Shortage of Information. In the following humorous utterance, Sam does not satisfy the real need of the farmer and he infringes the quantity maxim, he does not supply all the information needed for the conversation. Sam only tells the farmer what medicine he feeds his horse and does not mention anything about the effect. But the farmer has not realized that Sam violates the quantity maxim and is cheated by Sam.

One farmer meets Sam and says, "Hey, Sam, my horse's got distemper. What did you give yours when he had it?"

"Turpentine." grunted Sam.

"So did mine," Sam answered.

Too much Information. In this humorous article, the shop assistant just told Ted in general that hot coffee and popsicle are put together and the author realizes the humorous effect in this way.

Alice and Ted went snowboarding, and Ted brought along a quart-size thermos. Alice had never seen one, and asked what it was.

"It's a thermos," replied Ted. "The guy at the store told me it's used for keeping hot things hot and cold things cold."

Sounds good." said Alice. "What do you have in it?"

"Three coffees and a popsicle."

Violating the Quality Maxim and Humor. The quality maxim means the utterance content is real and actual. When the speaker or the author violates the quality maxim on purpose, that is, articulates something false, it will employ some rhetorical devices, such as, hyperbole, irony, metaphor, which is also a way to express humor.

She gave me the impression of having more teeth, white and large and even, than were necessary for any practical purpose.

This sentence "having more teeth, white and large and even, than were necessary for any practical purpose." is quoted from the short novel "The luncheon" by W. Somerset Maugham, who is a famous English writer. The author disobeys the quality maxim, employs the rhetorical way of hyperbole to describe how greedy, gluttonous and lazy the woman is with some jocularity and humor.

Violating the Relation Maxim and Humor. The relation maxim refers to being related to the topic, that is, related to the intention to be fulfilled. If the relation maxim is violated, the conversation will go astray and pause, humor and amusement will emerge. For example:

Mother said, "Doctor, come at once! Our baby swallowed a fountain pen!"

Doctor said, "I'll be right over. What are you doing in the meantime?"

Mother said, "Using a pencil."

When the doctor asked the mother what first aid measure should be taken, the mother answers unexpectedly," Using a pencil." This answer distorts what the doctor means, which is a totally unrelated answer. As the fountain pen had already been swallowed by the baby, the mother chose a pen as the substitute. The irrational and illogical answer does not focus the conversation on the endangered baby, but on the fountain pen and the pencil, which should not the focus of the conversation. It is just the totally unrelated answer that makes the conversation humorous and facetious.

Violating the Manner Maxim and Humor. If we can say "the quantity maxim", "the quality maxim", and "the relation maxim" center on the aspect of "what to speak", "the manner maxim" is about "how to speak". If the speaker takes no consideration of the context requirement, such as object, occasion, topic, and misuses words and tones, thus creating disharmony in the speaking pattern and speaking content, humor comes into being.

A friend and her young son, Reid, were browsing in a large bookstore. Engrossed in making a selection, my friend had lost sight of her child, "Reid!" She called out.

"Reid!" Just as she spotted the boy, she bumped into another customer. "Pardon me, Ma'am," he said, "but most folks come here because they always like to read. No sense in wasting your time trying to convince them."

The joke infringes the maxim of avoiding ambiguity of the manner maxim and brings out the 
humorous effect. The name Reid is similar to "read" in pronunciation. The customer bumped down is very humorous. He pretends that that the mother called her son "Reid" is persuading customers to read books. This can release the lady's embarrassment of bumping down the man and also defuses his own unhappiness of being bumped down.

\section{Verbal Behavior and Humor}

Austin puts out the famous speech act theory, including three types of verbal behavior, namely, locutionary act, illocutionary act, and perlocutionary act [12]. The theory explains successfully the linguistic phenomenon that humans often express themselves in a roundabout way of talking or give instructions in an indirect and tactful way. In order to understand such utterances, the two communicative sides must possess common information (background knowledge) and the communication must be carried out in some particular context. In the process of comprehending the speakers' indirect words or instructions, if the receiver can not catch up the meaning, the communication would be blocked, thus bringing about a humorous effect. For example:

Customer: Waiter, what's this fly doing in my soup?

Waiter: Oh, it's swimming, sir.

The illocutionary act is that the customer expresses his complaint towards the shop service; therefore the perlocutionary act should be that the waiter should make an apology to the customer, and change the soup. However, the perlocutionary act is avoided on purpose, and the locutionary act is highlighted, that is, the waiter merely takes the customer's question as offering some information about the soup. Thus, the humorous effect is created.

\section{Conclusion}

In different contexts, people's understanding of the referential expression, prerequisite, utterance meaning, utterance behaviors and the connectionist theory may cause some deviation or some dislocation; hence these pragmatic factors are the main reasons to generate the humor effect. It is said that humor is a lubricant among people's communication. Besides, humor is an important symbol of pragmatic ability of a language. Having a good knowledge of these pragmatic factors and the influencing mechanism on English humorous language is of some theoretical significance in humor language research, and it can be some guide for people to better grasp communicative methods and effect, enhance communicative efficiency.

\section{References}

[1] Https://en.wikipedia.org/wiki/Humour

[2] Joann a Channel, Vague Language, M. Shanghai: Shanghai foreign education publishing house, 2000 .

[3] William Morris, editor. The American Heritage Dictionary of Current English (the fourth edition), M. Houghton, 2000.

[4] Huimin Shi, Analyzing modern humor communication from the perspective of pragmatics, J. Modern communication, 2012, 340(8):36-37. (In Chinese)

[5] Yan Li, The pragmatic analysis of English humorous utterance, J. Jilin provincial educational university school magazine, 2013(1). (In Chinese)

[6] Ting Wang, The pragmatic analysis of representative short novels of Mark Twain, D. Zhejiang Normal University, 2012. (In Chinese)

[7] Bo Zhang, Analyzing the utterance meaning of Mansfield Park using the cooperative principle and politeness principle, D. Inner Mongolia University, 2012. (In Chinese)

[8] Lei Zhou, The utterance analysis of conversational utterance, M. Shanghai: Shanghai foreign 
education publishing house, 2013. (In Chinese)

[9] Libin Fan, Chunxia Wang. The exploration and explanation of English humor from the pragmatic principle perspective - from the perspective of the cooperative principle and connectionism theory, J. Social science united frontier, 2012(12). (In Chinese)

[10] Guihua Luo, Dongmei Zeng, The violation of conversation structure and the production of humor, J. Hunan social sciences, 2013(2). (In Chinese)

[11] Grice, H. P. Studies in the Way of Words, M. Beijing Foreign language Teaching and Research Press, 2002

[12] Austin, J.L, How to do things with words, L. Harvard U.P. 1962. 